EDITOR,-A B Kay notes the lack of any validation of the diagnostic methods and treatments used by some practitioners of clinical ecology and the possibility of dangerous adverse reactions.' $\mathrm{He}$ does not devote space to what may be the most disturbing aspect of all-namely, the failure appropriately to diagnose conditions, which inevitably leads to the denial of appropriate treatment and the reinforcement of maladaptive behaviours.

I and many of my colleagues who work - in general hospital psychiatry often see patients who have spent years, and considerable sums of money, seeing alternative allergy practitioners for little benefit. Such patients are often suffering from various psychological disorders, in particular depression, anxiety (with or without hyperventilation), or somatisation disorder. Formal studies confirm that most patients who have been labelled as having "twentieth century disease" or "environmental illness" fulfil criteria for psychiatric disorders. ${ }^{2-5}$

The tragedy is that many of these disorders are easily diagnosed; all that is required is to take an adequate history and perform a mental state examination, procedures that are cheap and free from side effects. Once diagnosed, many of these disorders are easily treated. Failure to diagnose them denies patients simple and effective treatment. On the other hand, providing a false diagnosis adds to patients' disability, reinforces maladaptive behaviour, and ensures that what might have been a brief illness becomes refractory to treatment. Furthermore, some of the techniques used by clinical ecologists, which centre on avoiding environmental stimuli, can worsen psychological distress and physical disability. The cure may be worse than the disease.

Such practices are costly to the patient, and not only in terms of money. In a well publicised case a patient recently committed suicide while under the care of a clinical ecologist. ${ }^{\circ}$ The government white paper The Health of the Nation identifies the need to reduce suicide rates as a key goal for public health. Improving medical recognition of depressive disorders, especially when they present, as most do, with somatic symptoms, is one way. Addressing the public stigma of mental illness, which permits the unscrupulous to collude with vulnerable patients, is another.

Department of Psychological Medicine,
King's College School of Medicine and

SIMON WESSELY \section{the Institute of Psychiatry,}

London SE5 9RS

1 Kay AB. Alternative allergy and the General Medical Council. $B M \mathcal{F}$ 1993;306:122-4. (9 January.)

2 Black D, Rathe A, Goldstein R. Environmental illness: a Black D, Rathe A, Goldstein R. Environmental illness: a
controlled study of 26 subjects with "20th century disease." IAMA 1990;264:3166-70.

3 Simon G, Katon W, Sparks P. Allergic to life: psychological factors in environmental illness. Am f Psychiatry 1990;147: 901-6.

4 Stewart D. Emotional disorders misdiagnosed as physical illness: environmental hypersensitivity, candidiasis hypersensitivity, and chronic fatigue syndrome. International foumal of Mental Health 1990;19:56-68.

5 Stewart D, Raskin J. Psychiatric assessment of patients with "20th-century disease" ("total allergy syndrome"). Can Med Assoc f 1985;133:1001-6.

6 Dunn E. Too ill to live: not ill enough to die. Daily Telegraph 1989 March 23.

EDitor,-A B Kay's account of the General Medical Council's recent hearing on the case of Dr Keith Mumby raises many important issues.'

There are many clinical situations in which some form of food sensitivity should be included in the differential diagnosis, ${ }^{2}$ but to entertain only food sensitivity as a diagnostic possibility is surely unreasonable. Dr Mumby stated that he diagnosed food or environmental allergy in more than $99 \%$ of his patients. He does not consider it necessary to examine the patients who consult him, and he seemed unaware that he might be failing to detect serious conditions, symptoms of which a patient might erroneously have associated with diet.

When clinical ecologists see patients with many symptoms, incongruity and inconsistency between their symptoms and clinical signs, and no laboratory evidence of disease they may diagnose environmental illness, food allergy, chronic fatigue syndrome, hypersensitivity to candida, or hypoglycaemia. The conventional view is that some polysymptomatic patients have a psychologically based disability. ${ }^{34}$ These patients are extremely suggestible. ${ }^{5}$ In a study of 50 such patients in the United States 15 developed new symptoms and some acquired additional "sensitivities" during two years of treatment of their environmental illness by clinical ecologists. ${ }^{\circ}$

If the disability is psychologically based diagnostic systems based on the use of multiple and unvalidated skin tests may reinforce the delusion. In order that satisfactory treatments can be developed, proper studies need to be carried out on those subjects who have psychologically based reactions to foods, however manifested. These may be the result of suggestion, but adverse conditioning is an entirely plausible further mechanism.

Western General Hospital,

ANNE FERGUSON Edinburgh EH4 2XU

1 Kay AB. Alternative allergy and the General Medical Council. $B M 7$ 1993;306:122-4. (9 January.)

2 Metcalf D, Simon R, Sampson HA, eds. Adverse reactions to foods and food additives. Cambridge, Mass: Blackwell, 1992.

3 Stewart DE. The changing faces of somatization. Psychosomatics 1990;31:153-8.

4 Quill TE. Somatization disorder: one of medicine's blind spots. IAMA 1985;254:3075-9.

5 Ferguson A. Food sensitivity or self-deception? $N$ Engl $f \mathrm{Med}$ 1990;323:476-8.

6 Terr AL. Environmental illness. A clinical review of 50 cases. Arch Intern Med 1986;146:145-9.

7 Robinson J, Ferguson A. Food sensitivity and the nervous system: hyperactivity, addiction and criminal behaviour Nutrition Research Reviews 1992;5:203-23.

EDrToR,-A B Kay deserves support in his attempt to persuade the General Medical Council (GMC) to provide far more effective protection for members of the public in relation to doctors who publicise treatments of unproved efficacy.' My experiences suggest that an increasing number of doctors are becoming involved in the promotion of dubious treatments, either by acting as medical advisers to companies or through their association with clinics providing unorthodox treatments.

Last year I thought it necessary to criticise several doctors for such behaviour. In one case the doctor's name appeared in a promotional brochure as medical adviser to a company marketing an electrical device that was claimed successfully to treat a range of conditions including migraine, arthritis, insomnia, and depression. These claims were purely anecdotal, and none had been verified by independent clinical trials. According to the brochure, this device was available-at a cost of $£ 155$ plus "consultation fee"-from several named medical practitioners, including the allergist named by Kay.

I am also aware of another practitioner who is planning to set up a clinic with a treatment based on an electronic system in which "free electrons are pumped into the body by the billions"-a claim that may sound impressive to members of the lay public. According to this clinic's publicity material, the results have been outstanding in a range of conditions including AIDS, cancer, heart disease, and even quadriplegia. Once again there is no evidence from independent clinical trials to back up the hype.

The 1968 Medicines Act gives the public perfectly adequate protection from false advertising claims made by companies that manufacture products classified as medicines. Unfortunately, through gullible journalists and limitations of the act, grossly exaggerated therapeutic claims can be made for "natural" health supplements, herbal remedies, electrical devices, allergy treatments, etc, few of which are ever supported by objective scientific evidence.

Obviously the GMC cannot investigate the efficacy of every controversial treatment brought to its attention. What it must now do is issue some clear guidelines on the manner in which doctors involve themselves-directly or indirectly-in promoting unproved remedies to the general public.

Friars Cottage Surgery,

CHARLES SHEPHERD

Chalford Hill,

Gloucestershire GL6 8EH

1 Kay AB. Alternative allergy and the General Medical Council. $B M F$ 1993;306:122-4. (9 January.)

EDITOR,-I was heartened by the stance taken by Richard Smith and A B Kay concerning controversial treatments and the General Medical Council (GMC).' 2 As a psychiatrist I sometimes explain to people the differences between my profession and that of psychology. There is a confusion in the public mind between the two, even among professionals. I believe that the long training that doctors undergo enables psychiatrists to diagnose and prescribe better than those without this training. Although there is logic behind this statement, it often provokes argument. It suits some members of the multidisciplinary mental health team, including some doctors, to underplay the importance of these skills. In the United States there has been a longstanding debate over prescribing rights for psychologists.

I have approached the GMC three times about professional boundaries, but it has been unable to help. The first approach concerned a stress management clinic advertising a consultant psychologist. The psychologist in question was not an NHS consultant, but I thought that the public might infer this. The Advertising Standards Authority upheld my complaint and ruled that the advertisements should be amended to clarify the matter. I approached the GMC again about ayurvedic medicine, which is allied to transcendental meditation. This concerned pulse diagnosis by doctors and herbal prescriptions to prolong life. The third referral concerned a chiropractor, a graduate of a European college, who styled himself doctor. His advertisements claimed that spinal misalignment caused various illnesses. His promotional leaflets referred to his routine practice of obtaining $x$ ray films, running diagnostic tests, and prescribing treatment. The GMC could not act because he had not specifically stated that he was a registered medical practitioner. Any patient seeing this man would have to check his claims to be a doctor themselves.

The public has to distinguish between highly qualified professionals like psychiatrists and psychologists at one end of the range and, at the other end of the range, discriminate between self styled doctors untrained in diagnosis and registered medical practitioners. Should the general public be left alone to make their own decisions, when presented with unproved techniques? I am well aware of the GMC's circumscribed functions in maintaining a register, and regulating the practice, of medically qualified doctors. Despite this the government needs to give some thought to the practices of doctors not on the medical register.

Royal Liverpool University Hospital,

B H GREEN

Liverpool L7 8XP

1 Smith R. GMC in the dock again. BMF 1993;306:82. (9 January.)

2 Kay AB. Alternative allergy and the General Medical Council. BMF 1993;306:122-4. (9 January.) 